[DT]

\title{
A new Mesozoic apparent polar wander loop for South China: paleomagnetism of Middle Triassic rocks from Guizhou Province
}

\author{
Zhongmin Wang ${ }^{a}$, Rob Van der Voo ${ }^{a}$ and Yanggeng Wang ${ }^{\mathrm{b}}$ \\ ${ }^{a}$ Department of Geological Sciences, University of Michigan, Ann Arbor, MI 48109-1063, USA \\ ${ }^{b}$ Guizhou Geological Bureau, Guiyang, China
}

Received June 14, 1992; revision accepted December 15, 1992

\begin{abstract}
Middle Triassic marine platform carbonates and sandstones in southeastern Guizhou province (South China Block) were sampled for a paleomagnetic study. A total of 91 samples from 14 sites were collected, including sandstone samples from two limbs of a fold. Progressive thermal demagnetization isolated single characteristic component magnetizations in the limestone unit and two components in the sandstones; all components show mixed polarities. The mean direction in the limestone unit is $352 /-34$ (in-situ) and $1 /-4$ (tilt-corrected) $\left(\alpha_{95}=12^{\circ}\right)$. Component 1 in the sandstones isolated within higher temperature ranges exhibits consistent directions in five sites out of six, yielding an overall site mean direction of $36 / 75, k=10, \alpha_{95}=45$ (in-situ) and 355/13,k =178, $\alpha_{95}=5.2$ (tilt-corrected) and passes a fold test at the $99 \%$ confidence level. The directions of component 2 with lower unblocking temperatures in the sandstones are best grouped at $10 \%$ unfolding ( $k=278, \alpha_{95}=6$ ), giving a mean direction of $351 / 18$ that conforms to the mean directions of the characteristic component in the limestone unit as well as component 1 in the first five sandstone sites. Our interpretation, therefore, is that all the magnetizations in the both limestones and the sandstones were acquired at the time of folding. Our paleomagnetic directions from Guizhou are similar to those of Paleozoic rocks, from which folding associated remagnetizations were also observed, in the vicinity of Nanjing in the northeastern part of the Yangtze Block. The folding associated remagnetizations in both areas thus most likely have the same age, i.e., Late Triassic/Jurassic. We further infer that the southern Guizhou province has not been rotated since Late Triassic/Jurassic times by considering the similarity of the pole positions obtained from remagnetizations in Yunnan, Guizhou and the Nanjing area. Moreover, we suggest a new early Mesozoic apparent polar wander loop for the South China Block, going through the poles of the Triassic/Jurassic remagnetizations. This loop points to rotations of the South China Block as a whole during the late Triassic-Jurassic period.
\end{abstract}

\section{Introduction}

Asia is a composite continent formed by the accretion, mainly during Phanerozoic times, of various crustal blocks [1,2]. The geographical entity of China is composed of several relatively stable cratons, such as Tarim, Sino-Korea and Yangtze, apparently welded and bounded by mobile fold belts [3]. South China consists of at least two ancient tectonic units, i.e., the Yangtze craton or paraplatform that has been in existence since at least middle Proterozoic times and the Huanan Fold Belt (Fig. 1). The tectonic framework of South China has classically been described using the term "paraplatform" on the basis of geosynclinal theory and the episodic nature of orogeny [4,5]. Recently, Hsu et al. [6-9] have argued that South China is not a single post-Caledonian platform, but a composite of blocks and orogenic belts with a pattern similar to that of the Appalachian Mountains. They hypothesize that this late Proterozoic/Mesozoic entity is a collage of three continental fragments - Yangtze, Huanan and Dongnanya. According to their tectonic evolutionary model for South China, Huanan and Yangtze were widely separated by an ocean during the Paleozoic and they sutured and collided during the Triassic. The post-Triassic tectonic stage is characterized by large-scale thin-skinned overthrusting of the Hua- 
nan Fold Belt onto the deformed Yangtze craton. This idea, however, has been criticized by many others [e.g., 10] who argue that Huanan and Yangtze were sutured during the Late Precambrian/early Paleozoic times and that Mesozoic overthrusting only occurred locally.

Relative displacement resulting from largescale overthrusting between the two tectonic units cannot be tested by paleomagnetic inclination data from the two sides, but a preceding (Paleozoic?) separation involving an ocean between them may be testable. On the other hand, paleomagnetic declinations would be suitable for de- tecting such overthrusting if it were accompanied by block rotations. Several previously published studies have yielded characteristic magnetizations from Triassic rocks in widely separated localities in South China (see Table 1 for references and Fig. 2 for localities) which appear to have yielded reliable reference paleopoles for the Triassic of the Yangtze region. Zhai and Seguin [11], on the other hand, reported a Triassic result (Table 1) that is significantly different from the reference poles for the Yangtze region. Their rocks come from Fujiang province (Fig. 2) which is thought to be part of the Huanan Fold Belt. They claim

TABLE 1

Paleomagnetic data of the Triassic for the South China Block

\begin{tabular}{|c|c|c|c|c|c|c|c|c|c|}
\hline \multirow[t]{2}{*}{ Rock unit } & \multirow[t]{2}{*}{ Lat } & \multirow[t]{2}{*}{ Long } & \multirow[t]{2}{*}{$N$} & \multirow[t]{2}{*}{$D$} & \multirow[t]{2}{*}{$I$} & \multicolumn{2}{|c|}{ Pole position } & \multirow[t]{2}{*}{$A_{95}$} & \multirow[t]{2}{*}{++} \\
\hline & & & & & & Lat. & Long & & \\
\hline \multicolumn{10}{|c|}{ Chan et al. (1984) } \\
\hline $\operatorname{Tr} 2$ & 26.0 & 106.0 & 8 & 216 & -26 & 64 & 221 & 7.5 & 3 \\
\hline $\begin{array}{l}\text { Lin et al. (1 } \\
\text { Changxing }\end{array}$ & 310 & 1198 & 13 & 45 & 45 & 51 & 205 & 68 & 2 \\
\hline \multicolumn{10}{|c|}{ Opdyke et al. (1986) } \\
\hline $\begin{array}{l}\operatorname{Tr} 1 \\
\text { Nanjing }\end{array}$ & 28.6 & 106.9 & 9 & 40 & 13 & 46 & 219 & 11 & 1 \\
\hline $\operatorname{Tr} 3$ & 32.0 & 119.0 & 23 & 225 & -24 & 45 & 222 & 9.3 & 4 \\
\hline \multicolumn{10}{|c|}{ Steiner et al. (1989) } \\
\hline $\operatorname{Tr} 1$ & 24.9 & 106.3 & $62 *$ & 50 & 17 & 39 & 210 & 4.1 & 6 \\
\hline \multicolumn{10}{|c|}{ Heller et al. (1988) } \\
\hline $\operatorname{Tr} 1$ & 32.4 & 106.4 & - & 36 & 14 & 48 & 225 & 5.0 & 5 \\
\hline \multicolumn{10}{|c|}{ McElhinny et al. (1981) } \\
\hline $\operatorname{Tr} 1$ & 27.3 & 105.9 & - & - & - & 52 & 243 & & 7 \\
\hline \multicolumn{10}{|c|}{ Zhai and Sequin (1990) } \\
\hline $\operatorname{Tr} 1$ & 26.0 & 117.2 & 17 & 336 & 5 & 57 & 346 & 7.9 & 9 \\
\hline \multicolumn{10}{|l|}{ This study } \\
\hline Zhengfeng & $\begin{array}{l}25.3 \\
\text { mpon }\end{array}$ & 105.3 & $17 *$ & 1 & -4 & 63 & 283 & 12 & $8 \mathrm{~L}$ \\
\hline & 25.3 & 105.4 & 5 & 355 & 13 & 70 & 300 & 5.2 & $8 \mathrm{~S}$ \\
\hline Zhengfeng & $\begin{array}{l}\text { mpon } \\
25.3\end{array}$ & 105.4 & 4 & 351 & 18 & 71 & 315 & 6.2 & 8SS \\
\hline
\end{tabular}

* Number of the samples used for calculation of the mean

++ Reference numbers for results (corresponding to the numbers in Figs. 2 and 8). 


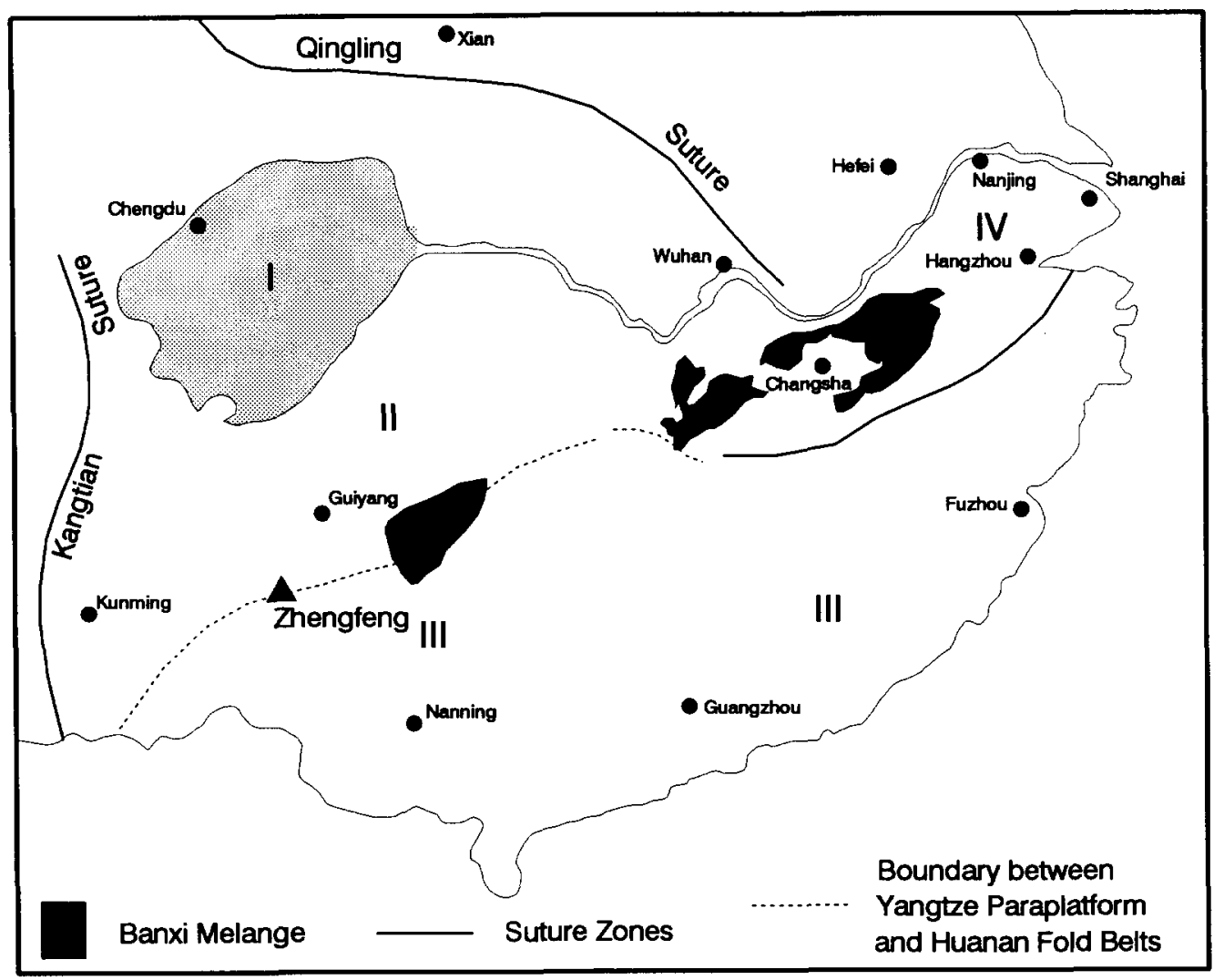

Fig. 1. Tectonic units of South China (simplified after Hsu et al. [6,7]). $I=$ Sichuan Basin; $I I$ and $I V=$ Yangtze Deformed Belt; $I I I=$ Huanan Folded Belt. Note that the Banxi Melanges (black) have been interpreted [6] as part of an accretionary wedge on the late Proterozoic/early Paleozoic Huanan active margin that later was overthrust onto the Yangtze Deformed Belt during the Mesozoic. Zhengfeng is the area of our sampled Triassic sections.

their result as support for the overthrusting tectonic theory proposed by Hsu et al [6-9] and conclude that the Huanan Fold Belt has been rotated counterclockwise relative to the Yangtze block since the Triassic.

Our sampling area in southern Guizhou province is located in the western border area between the Yangtze deformed margin and the Huanan Fold Belt (Fig. 1) and is confined by two major deep faults, the Beipanjiang fault in the north and the Nanpanjiang fault in the south. It is not clear whether this area is the southern margin of the Yangtze region or part of the Huanan nappe. Moreover, Mesozoic activity of the boundary faults and/or Mesozoic overthrusting, if they occurred, may have caused local rotations of this area. We collected samples of Middle Triassic rocks from fourteen sites in Zhengfeng county of southern Guizhou province in order to compare the paleomagnetic data with those previously published for the Yangtze Block (and its margins) and to identify possible rotations in this area since the Middle Triassic.

We have reported folding associated remagnetization results, with ages assumed to be Late Triassic/Jurassic, from the Paleozoic rocks located in the vicinity of Nanjing [12]. The remagnetizations yield a pole that does not fall on the preliminary polar wander path for South China. To test whether similar remagnetizations prevail in other rocks of South China is naturally another purpose of this study.

\section{Geological setting and sampling}

We visited two Middle Triassic sections in Zhengfeng county. One consists of monoclinal limestone beds that dip $25-45^{\circ}$ to the south. 
Another section, located to the north of the limestone unit, is a $500 \mathrm{~m}$ exposure of fossiliferous grey sandstone deformed into a noncylindrical anticline with the north limb dipping at $45-65^{\circ}$ to the northwest and the south limb $45-70^{\circ}$ to the southwest. The timing of the folding of these formations is not clear because no younger lithified rocks are observed, except for a thick section of Cenozoic sediments, but, based on knowledge of the tectonic history of the region it may well be early Jurassic (early Yanshanian orogeny) [30]. There is only a distance of $<100 \mathrm{~m}$ between the exposed limestone and sandstone. These formations are inferred to be in contact with each other beneath the Cenozoic sediment cover, with the limestone unit appearing to unconformably over- lie the sandstone unit. Two hypotheses have been suggested for this pattern, although neither has been checked by convincing geological field data. One involves a lithological facies transition from a carbonate marine facies to a proximal clastic facies. This interpretation, however, is not supportable owing to the lack of a mixed facies zone in the region. The other interpretation is that the limestone unit has been overthrust onto the sandstone unit, but this seems to be somewhat speculative because no evidence has thus far been obtained for faulting between the two units.

A total of 91 individual oriented samples were collected from fresh road cuttings using a portable petrol-powered drill and a magnetic compass. The limestone unit yielded 50 samples at 8 sites and

\section{TABLE 2}

Triassic paleomagnetic results from Zhengfeng, south Guizhou province

\begin{tabular}{|c|c|c|c|c|c|c|c|}
\hline Site & $S t / D p$ & $n / N$ & $\begin{array}{r}\text { In-situ } \\
D / I\end{array}$ & $\begin{array}{l}\text { Tilt-corrected } \\
D / I\end{array}$ & $k_{2}$ & $\alpha_{95}$ & $k_{2} / k_{1}$ \\
\hline \multicolumn{8}{|c|}{ Sandstone component 1} \\
\hline $\mathbf{R} 1$ & $245 / 54$ & $5 / 7$ & $214 /-65$ & $177 /-21$ & 15.9 & 18 & - \\
\hline $\mathrm{R} 2$ & $245 / 53$ & $4 / 7$ & $196 /-58$ & $176 /-11$ & 27.6 & 17 & - \\
\hline R3 & $265 / 65$ & $3 / 5$ & $350 / 75$ & $353 / 9$ & 25.4 & 19 & - \\
\hline $\mathrm{R} 4$ & $242 / 54$ & $4 / 6$ & $17 / 64$ & $356 / 16$ & 27.9 & 17 & - \\
\hline R5 & $105 / 69$ & $4 / 10$ & $155 / 54$ & $352 / 8$ & 26.0 & 18 & - \\
\hline $\mathbf{R} 7 *$ & $135 / 46$ & $6 / 6$ & $198 / 41$ & $205 /-2$ & 43.1 & 10 & - \\
\hline \multicolumn{8}{|c|}{ Mean Sst. component 1} \\
\hline & & $5 / 6$ & $36 / 75$ & $355 / 13$ & 178.0 & 5 & 17.8 \\
\hline \multicolumn{8}{|c|}{ Sandstone component 2} \\
\hline $\mathrm{R} 1$ & $245 / 54$ & $5 / 7$ & $349 / 26$ & $349 /-26$ & 305.0 & 4 & - \\
\hline $\mathbf{R} 2$ & $245 / 53$ & $4 / 7$ & $349 / 27$ & $349 /-25$ & 12.2 & 27 & - \\
\hline R3 & $265 / 65$ & $3 / 5$ & $355 / 21$ & $355 /-45$ & 39.6 & 20 & - \\
\hline R7 & $135 / 46$ & $3 / 6$ & $172 /-12$ & $153 /-35$ & 36.2 & 18 & - \\
\hline \multicolumn{8}{|c|}{ Mean Sst. component 2} \\
\hline & & $4 / 6$ & $341 / 22$ & $346 /-18$ & 5.5 & 44 & 0.05 \\
\hline \multicolumn{8}{|c|}{ Mean Sst. component $2,10 \%$ unfolding } \\
\hline & & $4 / 6$ & - & $351 / 18$ & 278.0 & 6 & $0.02^{\mathrm{a}}$ \\
\hline \multicolumn{8}{|c|}{ Limestone } \\
\hline L1 & $100 / 26$ & $4 / 6$ & $180 / 24$ & $181 /-2$ & 25.5 & 19 & - \\
\hline L2 & $95 / 26$ & $4 / 5$ & $155 / 16$ & $157 /-6$ & 11.9 & 27 & - \\
\hline L3 $3 *$ & $140 / 34$ & $0 / 8$ & \multicolumn{5}{|c|}{ all samples have low NRM intensities } \\
\hline $\mathbf{L} 4$ * & $105 / 32$ & $8 / 8$ & $359 / 48$ & $332 / 77$ & 107.0 & 5 & - \\
\hline $\mathbf{L} 5 *$ & $105 / 35$ & $6 / 6$ & $360 / 48$ & $317 / 78$ & 31.9 & 12 & - \\
\hline L6 * & $97 / 32$ & $5 / 5$ & $356 / 48$ & $341 / 80$ & 1496.0 & 2 & - \\
\hline R8 & $145 / 46$ & $4 / 6$ & $347 /-47$ & $8 /-14$ & 13.3 & 26 & - \\
\hline $\mathrm{R} 9$ & $123 / 41$ & $5 / 6$ & $2 /-46$ & $12 /-9$ & 12.7 & 22 & - \\
\hline \multicolumn{8}{|c|}{ Mean limestone } \\
\hline & & $17 / 23$ & $172 / 34$ & $181 / 4$ & 8.3 & 12 & 1.12 \\
\hline
\end{tabular}

\footnotetext{
* Indicates characteristic directions not used to calculate means; $S t / D p$ indicates bedding orientation; $n / N$ indicates number of samples used to calculate the means/number of the samples demagnetized; $D / I$ indicates declination and inclination. ${ }^{a} k_{2} / k_{1}$ is the ratio of precision numbers at $100 \%$ and $10 \%$ unfolding.
} 
the sandstone unit 41 samples at 6 sites. All the $2.5 \mathrm{~cm}$ diameter samples drilled in the field were cut into $2.2 \mathrm{~cm}$ high specimens. The bedding attitudes are summarized in Table 2 together with the paleomagnetic results that we obtained.

\section{Paleomagnetc results}

Measurements were carried out on a ScT cryogenic magnetometer, with alternating field $\mathrm{AF}$ and thermal demagnetizations performed on Schonstedt equipment at the University of Michigan, in a shielded room with a rest field less than $200 \mathrm{nT}$. Pilot (AF) and thermal demagnetizations showed that AF effectively reduces a significant part of the NRM intensity in fields up to $100 \mathrm{mT}$, but that thermal treatment was preferable because it provided better resolution of the demagnetization trajectories. Intensities of NRM range from 0.2 to $1.5 \mathrm{~mA} / \mathrm{m}$ and are independent of the lithologies sampled, except for one site in the limestone unit where all the samples have NRM intensities close to the magnetometer sensitivity. The samples of this site (L3) were disregarded without further treatment.

Thermal demagnetization indicates that all samples at three sites (L4, L5 and L6) of the

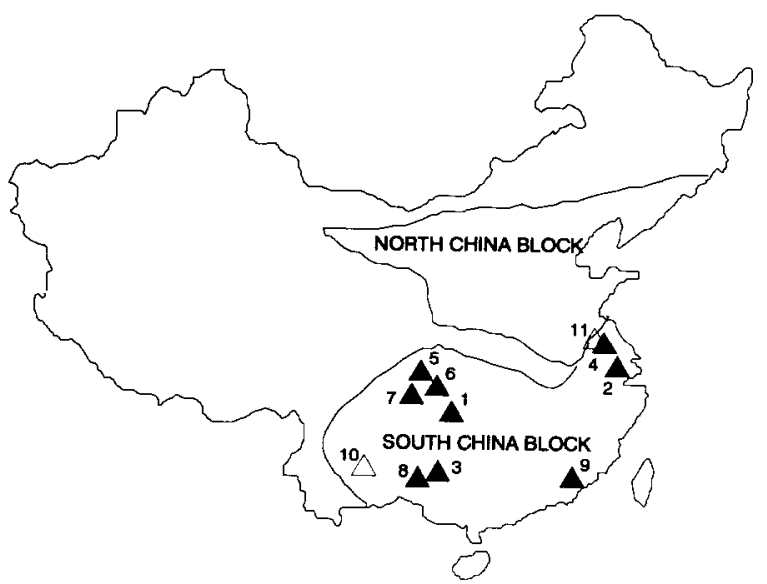

Fig. 2. Tectonic sketch-map of China (after Zhang et al. [14]), with the localities where Triassic paleomagnetic studies have been conducted for South China indicated ( $\triangle$ ),$I$ and $4=[15]$; $2=[16] ; 3=[17] ; 5=[18] ; 6=[19] ; 7=[20] ; 8=$ this study; $9=[11] . \Delta$ Localities where secondary (possibly TriassicJurassic) remagnetizations have been observed: $10=$ Meishucun in eastern Yunnan province [13]; $11=$ Nanjing [12]. limestone unit display univectorial directions conforming to the present day field (Table 1). At the remaining four sites (L1, L2, R8, and R9), a characteristic magnetization with northerly or southerly and shallow directions is successfully resolved from a majority of the samples (Fig. 3) after removal of an aberrant viscous component at low temperature. Both normal (Fig. 3B) and reversed (Fig. 3A) polarities are observed. The maximum unblocking temperatures of this component are well below $570^{\circ} \mathrm{C}$, indicating that it probably resides in magnetite only.

There is more variability in the magnetizations of the samples from the two limbs of the sandstone unit. A magnetization component with shallow inclinations and dual polarities in tilt-corrected coordinates, herein called component 1 , is isolated from 26 sandstone samples in the form of either univectorial vectors or higher temperature trajectories (Fig. 4). The sample directions of this component are plotted in Fig. 5A and the site means are listed in Table 1 . All site mean directions are nearly north-south and well-grouped, except for one site (R7) that displays a southsouthwesterly declination (Table 1). Stepwise unfolding (Fig. 5B) reveals that the precision parameter $(k)$ of the first five sites (R1-R5 in Table 1) reaches a maximum after complete correction for bedding tilt, indicating a pre-folding nature for component 1 residing in the sandstone unit. A Fisherian isolate vector test, on the other hand, shows that the probability that the mean direction of site R7 falls into the population constituted by the mean directions of the first five sites is almost zero. This could be taken to suggest that site $\mathrm{R} 7$ has experienced rotations relative to the other sandstone sites, or alternatively that component 1 resolved from site $\mathrm{R} 7$ and that from the other sites represent ancient geomagnetic fields with different ages. We will discuss this issue in the following section.

With few exceptions at site $\mathrm{R} 7$, the maximum unblocking temperatures of component 1 of the sandstone samples are also below $570^{\circ} \mathrm{C}$, indicating that the major magnetic carrier for this component is magnetite.

Another magnetization component, herein called component 2 , is seen in fifteen sandstone samples as lower temperature trajectories of demagnetizations. This component is often super- 
posed on component 1 (Fig. 6) and is unblocked at temperatures below $450^{\circ} \mathrm{C}$. The sample directions of this component are plotted in Fig. 7, with a stepwise unfolding curve illustrated (Fig. 7B). It is clear that the precision parameter $(k)$ reaches a maximum at $10 \%$ unfolding. We therefore infer that component 2 magnetizations in the sandstone unit are most likely syn- to postfolding. A mean direction for component 2, after $10 \%$ unfolding, is given in Table 2.

\section{L1-3}

R8-4
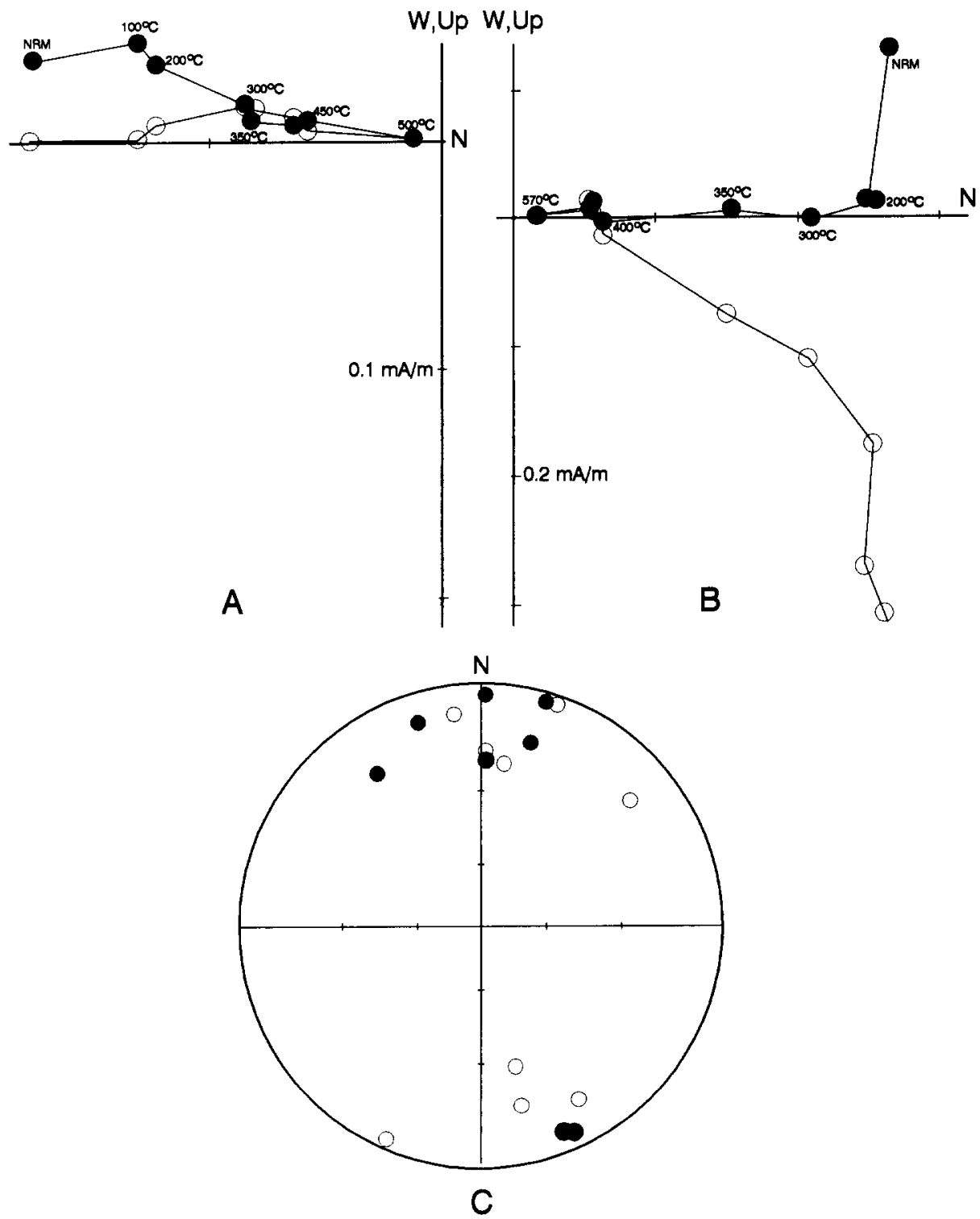

Fig. 3. (A and B) Orthogonal demagnetization diagrams representative of limestone samples displaying northerly and shallow tilt-corrected directions. (O) End points plotted on the vertical plane, $\bullet$ end points plotted on the horizontal plane. Values mark thermal demagnetization levels steps. (C) Equal-angle projection of the characteristic directions from the limestone samples after tilt correction. 


\section{Interpretation}

It can be seen in Table 2 that the characteristic magnetization in the limestone unit, the prefolding component 1 and the syn- to postfolding component 2 in the sandstone unit yield quite similar directions, i.e., nearly northerly or southerly and shallow. $F$-tests indicate that all of these directions are not significantly different at the $99 \%$ confidence level. It is reasonable to consider these directions as representing the same

\section{R1-5}

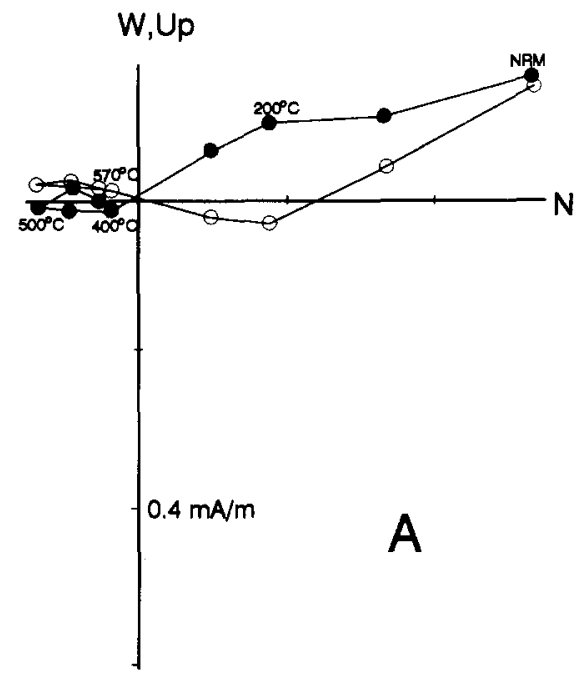

R3-4

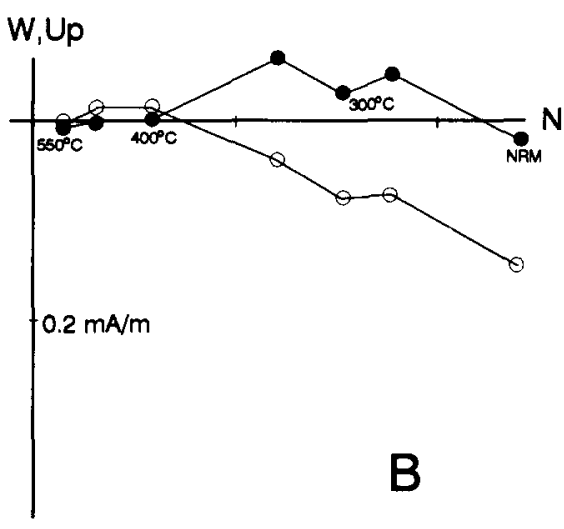

ancient geomagnetic field for southern Guizhou province. We further infer that all of these magnetizations were acquired at the time when the formations were folded and are they are therefore herein termed folding-associated remagnetizations; the characteristic magnetization in the limestone unit and the pre-folding component 1 in the sandstone unit were induced before or at an early stage of the folding process.

It is remarkable that the mean direction of component 1 isolated from site R7 in the sand-

\section{R7-3}

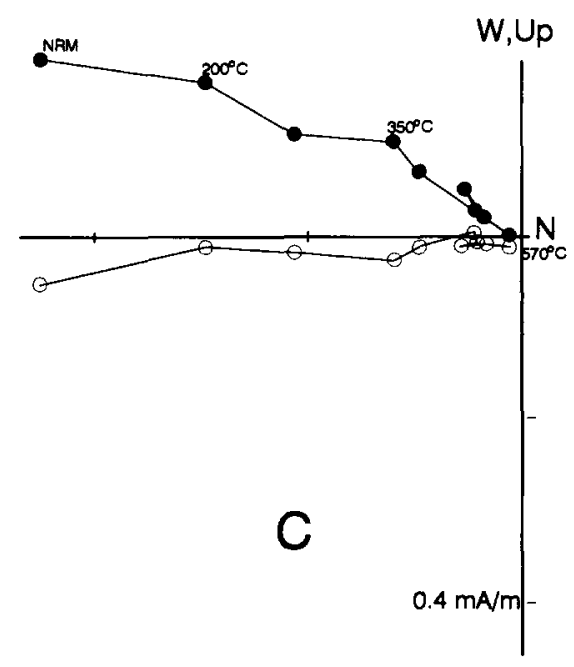

R7-5

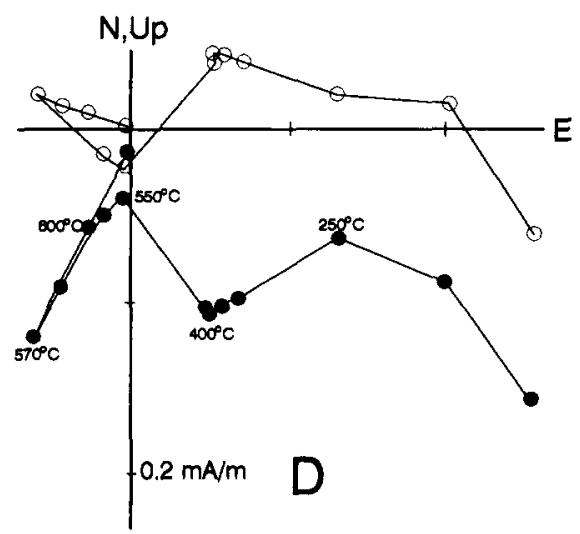

Fig. 4. Orthogonal demagnetization diagrams representative of the sandstone samples predominantly carrying component 1 magnetizations (tilt-corrected). Both polarities are observed in sample R1-5. Conventions as in Fig. 3A. Note that the declinations of samples R7-3 and R7-5 (both from site 7) are significantly different from those of the samples (e.g., R1-5 and R3-4) from the other sites. 
stone unit is significantly different from the overall mean direction of the folding-associated remagnetizations. This difference is seen in the more south-southwesterly declination of site R7. Two possible explanations for this declination inconsistency are, as mentioned earlier: (1) the strata at site $\mathrm{R} 7$ have experienced secondary clockwise bending relative to other sandstone sites studied in the area, considering that after a strike correction for site $\mathrm{R} 7$, the new mean direction of site R7 $(173 /-3)$ conforms to those of the remaining sandstone sites (Table 2), and (2) the acquisition time of component 1 in site $\mathrm{R} 7$ is different from those in the other sandstone sites. If the second interpretation is accepted, a paleomagnetic result with an age presumably older than that of component 1 at the other sandstone sites is obtained. This result would then be in agreement with other, previously published Triassic poles for the Yangtze region, indicating that southern Guizhou province has not been rotated relative to the Yangtze Block since the Triassic. Clearly, however, either of the explanations may be valid. In the absence of any other conclusive evidence about the nature of the magnetizations of site R7, it seems prudent to conclude that
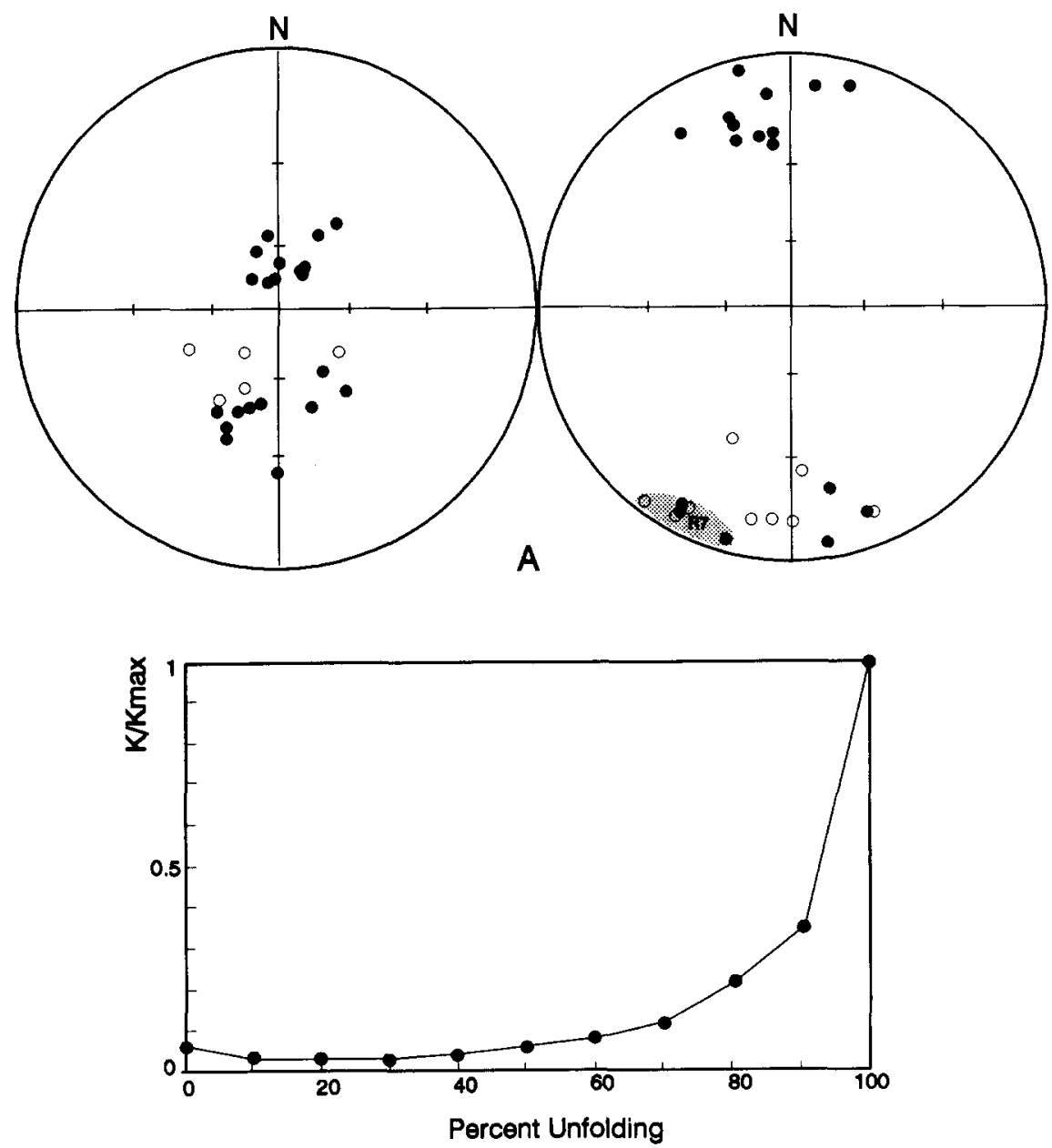

B

Fig. 5. (A) Equal-angle projections of the sample directions of component 1 isolated from the sandstones before (left) and after (right) correction for bedding tilt. Note that the sample directions of site R7 are generally more southwesterly than those of the other sites (see text for discussion). (B) The gradual increase of the precision parameter ( $k$, calculated from the site means excluding R7) with stepwise unfolding indicates a prefolding age of the component 1 magnetizations revealed by the sandstones. 
component 1 magnetizations isolated from site R7 as well as from the other sandstone sites represent the same geomagnetic field.

The Triassic paleomagnetic results thus far reported for South China are summarized in Table 2. In Fig. 8, the pole positions calculated from the magnetization components revealed from the Triassic rocks in southern Guizhou province are plotted together with a polar wander path for the Yangtze Block. Several Triassic poles that are consistent with each other have been reported for the Yangtze Block [15-20]. It is clear that the poles obtained from the folding-associated remagnetization results in the Triassic rocks in southern Guizhou province are significantly different from the previously published Triassic poles [15-20], as well as from the paleopoles thus far published for ages younger than Triassic for the Yangtze Block.

We have obtained similar folding-associated remagnetization results from Paleozoic rocks located in the vicinity of Nanjing [12]; similar results have also been obtained in the late Sinian/ early Cambrian rocks from east Yunnan province [13] and have been interpreted by us to be early
Mesozoic remagnetizations as well [29]. It is striking that the folding-associated remagnetization directions in the Triassic rocks of southern Guizhou province resemble those reported from the Nanjing and Yunnan areas, as shown by the paleopoles in Fig. 8. The paleolatitudes obtained from the folding-associated remagnetizations in all of these areas are near-equatorial and significantly different from the higher (more northerly) paleolatitudes for ages younger than Early Jurassic reported thus far for the entity of South China. It is not doubted, on the other hand, that the folding ages of the rocks in these areas must be younger than Middle Triassic. Therefore, we can bracket the age(s) of the folding-associated remagnetizations in all of the three areas to the (same) interval of late Triassic/Jurassic.

It is obvious that the difference between the Late Triassic poles for the South China Block and the poles calculated from the folding-associated remagnetizations is due principally to a declination variation (northeasterly and near-northerly, respectively). This can be taken to suggest (i) local rotations occurred in the areas studied, or (ii) apparent polar wander during an interval of

\section{R7-7}

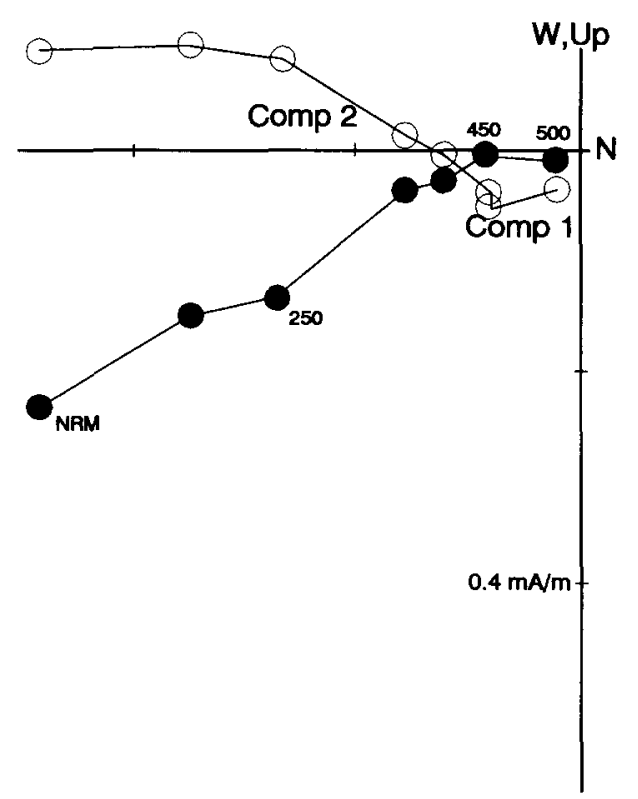

\section{R1-1}

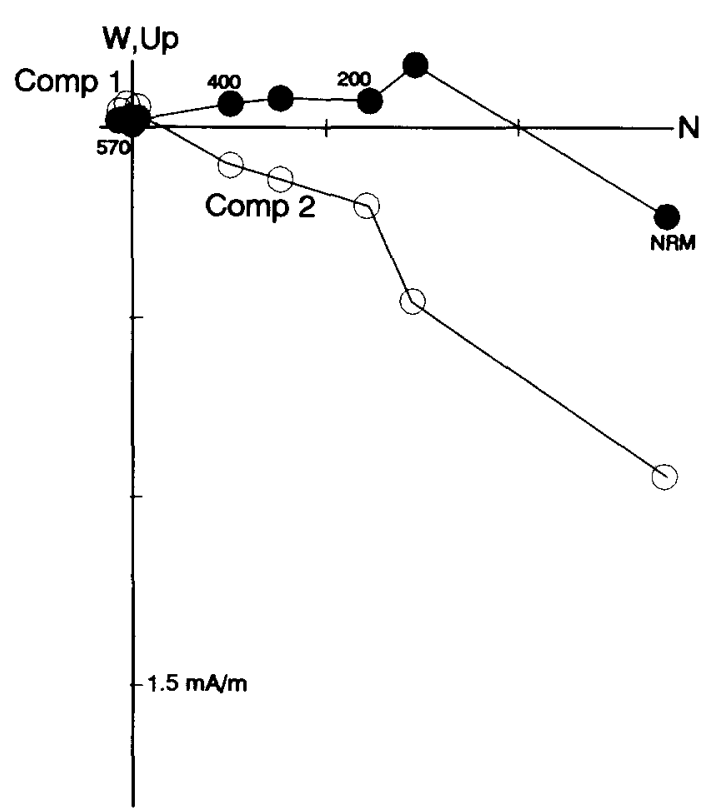

Fig. 6. Orthogonal demagnetization diagrams (in-situ) representative of the sandstone samples with component 2 magnetizations resolved as the lower temperature trajectories. Conventions as in Fig. 3A. Component 1 magnetizations are isolated at the higher unblocking temperature ranges for these samples. 
Triassic/Jurassic time. It should be pointed out that local rotations, while quite possible in theory, do not explain the coherent poles from Nanjing, southern Guizhou and eastern Yunnan (Fig. 8). This coherence suggests a rotation of south China as a whole, i.e., apparent polar wander. This means that a new loop must be included in the Apparent Polar Wander Path for South China, going through the poles calculated from the folding-associated remagnetization results obtained in the Nanjing area and the southern Guizhou and eastern Yunnan provinces (Fig. 8). The age of this loop is, as argued above, constrained to the late Triassic/Jurassic interval.

The modification that is made herein for the Mesozoic segment of the APWP for South China is preliminary. More compelling evidence for the loop will certainly depend on the acquisition of more Mesozoic paleomagnetic data. Its age calibration will depend, moreover, on more precise dating of the folding phases that deformed the rocks involved in our studies.
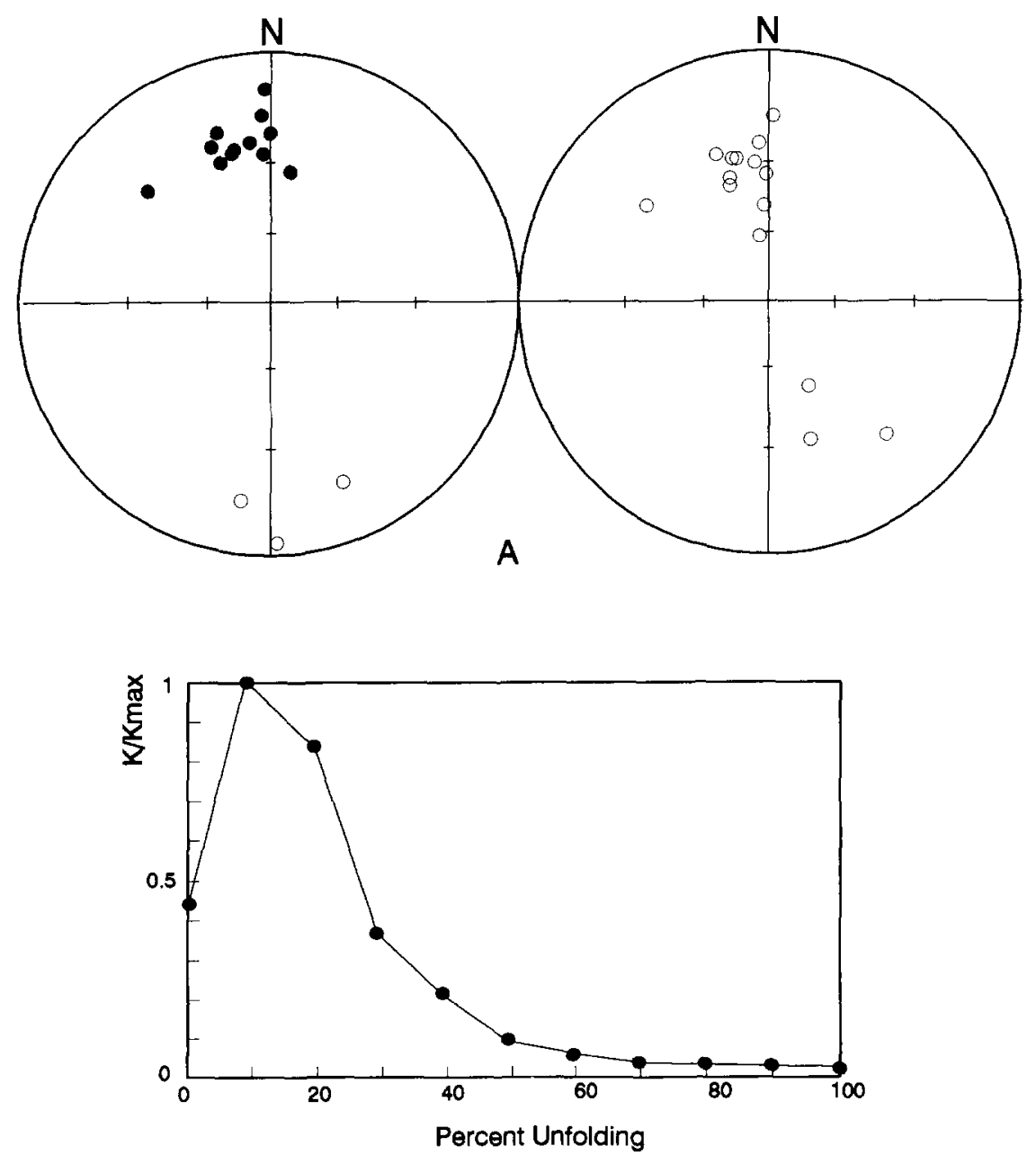

B

Fig. 7. (A) Equal-angle projections of the sample directions of component 2 isolated from the sandstone rocks before (left) and after (right) correction for bedding tilt. (B) The appearance of the maximum $k$ value at only $10 \%$ unfolding indicates that component 2 magnetizations isolated from the sandstones are most likely syn- or postfolding. 
We infer, further, that southern Guizhou province has not been rotated relative to the Yangtze Block since Jurassic times.

\section{Conclusion}

Middle Triassic formations in southern Guizhou province have experienced folding-associated remagnetizations. The directions of these remagnetizations conform to those of the folding-associated remagnetizations that we have observed in Paleozoic formations in the Nanjing area. We speculate that all of these folding-associated remagnetizations have roughly the same age, i.e., late Triassic/Jurassic.

By comparing the remagnetization poles for southern Guizhou province to those for the Nan- jing and Yunnan regions we infer that southern Guizhou province has not been rotated relative to the Yangtze Block since Jurassic times and most likely is part of the deformed Yangtze margin.

Based on the poles from this study, a new Mesozoic apparent wander loop for South China must be constructed. This loop indicates that the South China Block rotated in its entirety during Late Triassic/Jurassic times.

\section{Acknowledgements}

This research was supported by the Scott Turner Fund of the University of Michigan, and the Division of Earth Sciences, the National Science Foundation, grant EAR 88-16772.

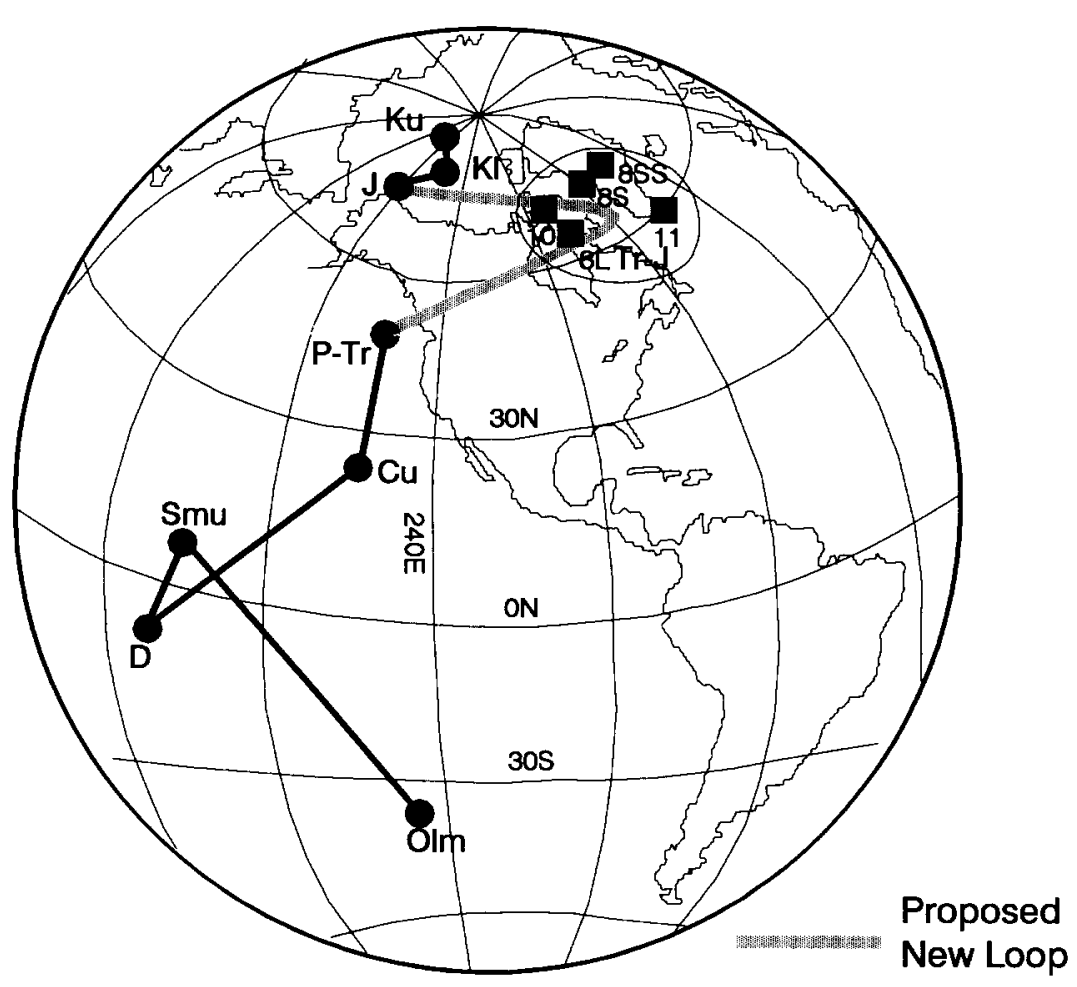

Fig. 8. Provisional Apparent Polar Wander Path for the South China Block. $K u=$ Late Cretaceous $[21,22] ; K 1=$ Early Cretaceous [16]; $J=$ Jurassic [16]; $P-T r=$ Permo-Triassic [15-25]; $C u=$ Late Carboniferous [16]; $D=$ Devonian [26]; Smu = middle /late Silurian [27]; $O l m=$ Early $/$ Middle Ordovician [28]. $8 \mathrm{~S}=$ The pole position calculated from the mean direction of component 1 in the sandstone rocks of this study, $8 \mathrm{~L}=$ The pole position calculated from the mean characteristic direction observed in the limestone samples of this study; $8 \mathrm{SS}=$ The pole position calculated from the mean direction of component 2 (secondary magnetization) in the sandstone samples of this study, $10=\mathrm{A}$ pole position reported by Fang et al. [13] from the Meishucun Precambrian/Cambrian boundary section; $11=$ A paleopole obtained from Paleozoic but remagnetized rocks with a folding age of Late Triassic/Jurassic? from the Nanjing area [12]. 


\section{References}

1 E. Argand, La tectonique de l'Asie, Proc. 13th Int. Geol. Congr. (Brussels), pp. 171-372, 1924.

2 A.H.G. Mitchell, Phanerozoic plate boundaries in mainland SE Asia, the Himalayas and Tibet, J. Geol. Soc. London 138, 109-122, 1981.

3 C. Li, Q. Wang, X.Y. Liu and Y.Q. Tang, Explanatory notes to the tectonic map of Asia, Cartographic Publ. Ho. China, Beijing, 1982.

4 W.B. Hamilton, Tectonics of Indoasian region, U.S. Geol. Surv. Prof. Pap. 1078, 245 pp., 1978.

5 H.Z. Wang (chief compiler), Atlas of Paleogeography of China, Cartographic Publ. Ho., Beijing, 1985.

6 K.L. Hsu, J. Li, H. Chen, Q. Wang, S. Sun and A.M.C. Sengor, Tectonics of South China: key to understanding west Pacific geology, Tectonophysics 183, 9-19, 1990.

7 K.L. Hsu, S. Sun, J. Li, H. Chen, H. Pen and A.M.C. Sengor, Reply to discussions, Geology 17, 669-673, 1989.

8 K.L. Hsu, S. Sun, J. Li, H. Chen, H. Pen and A.M.C. Sengor, Mesozoic overthrust tectonics in South China, Geology 16, 418-421, 1988.

9 K.L. Hsu, S. Sun and J. Li, Huanan Alps, not south China platform, Sci. Sin., Ser. B. 2, 1107-1115, 1987.

10 D.B. Rowley, A.M. Ziegler and S.Y. Nie, Mesozoic overthrust tectonics in south China: Hsuture or suture? - a discussion, Geology 17(4), 384-386, 1989.

$11 \mathrm{Y}$. Zhai and K. Sequin, Paleomagnetic evidence for the existence of Nanpanjiang sea between the Yangtze and Huanan blocks, China, EOS, Trans. AGU 105, 72, 1991.

$12 \mathrm{Z}$. Wang and R. Van der Voo, Pervasive remagnetization of Paleozoic rocks acquired at the time of Mesozoic folding in the South China Block, J. Geophys. Res., submitted, 1992.

13 W. Fang, R. Van der Voo and Q. Liang, Reconnaissance magnetostratigraphy of the Precambrian-Cambrian boundary section at Meishucun, China, Cuad. Geol. Iber.12, 205-221, 1989.

14 Zh.M. Zhang, M. Liou and R.G. Coleman, An outline of the plate tectonics of China, Geol. Soc. Am. Bull. 95, 295-312, 1984

15 N.D. Opdyke, K. Huang, G. Xu, W.Y. Zhang and D.V. Kent, Paleomagnetic results from the Triassic of the Yangtze Platform, J. Geophys. Res. 91, 9553-9568, 1986.

16 J.-L. Lin, M.D. Fuller and W.Y. Zhang, Preliminary Phanerozoic polar wander paths for the North and South China Blocks, Nature 313, 444-449, 1985.
17 L.S. Chan, Wang C.Y. and X.Y. Wu, Paleomagnetic results from some Permian-Triassic rocks from southwestern China, Geophys. Res. Lett. 11, 1157-1160, 1984.

18 F. Heller, W. Lowrie, H. Li and J. Wang, Magnetostratigraphy of the Permo-Triassic boundary section at Shangsi, China, Earth Planet. Sci. Lett. 88, 348-356, 1988.

19 M. Steiner, J. Ogg, Z. Zhang and S. Sun, The Late Permian/Early Triassic magnetic polarity time scale and plate motions of South China, J. Geophys. Res. 94: 7343$7363,1989$.

20 M.W. McElhinny, B.J.J. Embleton, X.H. Ma and Z.K. Zhang, Fragmentation of Asia in the Permian, Nature, $293,312-316,1981$

21 D.V. Kent, G. Xu, K. Huang, W.Y. Zhang and N.D. Opdyke, Paleomagnetism of Upper Cretaceous rocks from South China, Earth Planet. Sci. Lett. 79, 184-189, 1981.

22 K.N. Huang and N.D. Opdyke, Paleomagnetism of Lower Cretaceous to Lower Tertiary rocks from Southwestern Sichuan: A revisit, Earth Planet. Sci. Lett., submitted, 1992.

23 Z.K. Zhang and J. Zhang, Paleomagnetic study of the Upper Carboniferous basalt in the Baoshan block, Yunnan, Geol. Inst. Bull. Acad. Geol. Sci. 15, 183-189, 1986 (in Chinese with English Abstr.).

24 X.X. Zhao and R.S. Coe, Paleomagnetic constraints on the collision and rotation of North and South China, Nature, 327, 141-144, 1987.

25 K.N. Huang, N.D. Opdyke, G.Z. Xu and R.L. Tang, Further paleomagnetic results from the Permian Emeishan Basalt in SW China, Kexue Tongbao, 31, 1195-1201, 1986 (English Transl.).

26 W. Fang, R. Van der Voo and Q. Liang, Devonian paleomagnetism of Yunnan Province across the Shan ThaiSouth China suture, Tectonics 8, 939-952, 1989.

27 N.D. Opdyke, K. Huang, G. Xu, W.Y. Zhang and D.V. Kent, Paleomagnetic results from the Silurian of the Yangtze Paraplatform, Tectonophysics 139, 123-132, 1987.

28 W. Fang, R. Van der Voo and Q. Liang, Ordovician paleomagnetism of Eastern Yunnan, China, Geophys. Res. Lett., 17: 953-956, 1990.

29 Z. Wang, R. Van der Voo and Y. Wang, Paleomagnetic results from Late Sinian / Early Cambrian rocks in Guizhou province, South China Block, Tectonophysics, submitted, 1992.

30 J. Huang, J. Ren., C. Jiang, Z. Zhang and D. Qin, Tectonics of China and its Evolution, 27 pp., Scientific Publ. Ho., Beijing, 1980. 